\title{
Highly Diastereoselective Cyanation of Methyl Ketimines Obtained from (R)-Glyceraldehyde
}

Ramón Badorrey, Carlos Cativiela, María D. Díaz-de-Villegas, *’ Roberto Díez, Fabrizio Galbiati José A. Gálvez, *,

\section{Supporting Information}

\section{Contents:}

General Information $\quad$ S2

General procedure for the addition of trimethylsilyl cyanide to imines $\mathbf{1 a}-\mathbf{c} \quad$ S3

$\begin{array}{ll}\text { References } & \text { S4 }\end{array}$

${ }^{1} \mathrm{H}$ NMR and ${ }^{13} \mathrm{C}$ NMR spectra $\quad$ S5-S18

Thermal ellipsoid plot for compound anti-2a $\quad$ S19 


\section{General Information}

Materials: All reagents for reactions were of analytical grade and were used as obtained from commercial sources. Whenever possible the reactions were monitored by TLC. TLC was performed on precoated silica gel polyester plates and products were visualized using UV light (254 nm) and phosphomolybdic acid. Column chromatography was performed using silica gel (Kiesegel 60, 230-400 Mesh). (R)-2,2-Dimethyl-1,3-dioxolan-4-yl methyl ketone was prepared as previously described in the literature, ${ }^{1}$ Compounds 1a-c were prepared from (R)-2,2-dimethyl-1,3-dioxolan-4-yl methyl ketone according to literature procedures. ${ }^{2}$

General procedures: Melting points were determined in open capillary tubes and are uncorrected. FT-IR spectra of liquids were recorded as thin films on $\mathrm{NaCl}$ plates and FT-IR spectra of solids were recorded as $\mathrm{KBr}$ pellets, $v_{\max }$ values expressed in $\mathrm{cm}^{-1}$ are given for the main absorption bands. Optical rotations were measured in a cell with a $10 \mathrm{~cm}$ path length, concentrations are given in $\mathrm{g} / 100 \mathrm{~mL}$. Elemental analyses were performed using a C,H,N,S elemental analyser. ${ }^{1} \mathrm{H}$ NMR and ${ }^{13} \mathrm{C}$ NMR spectra were acquired at room temperature, except for compound 5 (registered at $328 \mathrm{~K}$ ), in $\mathrm{CDCl}_{3}$ at 400 and $100 \mathrm{MHz}$, respectively. The chemical shifts $(\delta)$ are reported in parts per million and the coupling constants $(J)$ in Hertz. The following abbreviations are used: s, singlet; d, doublet; q, quartet; dd, doublet of doublets; m, multiplet; bs, broad signal. NOESY spectra were acquired in the phase sensitive mode with gradient pulses in the mixing time as $2048 \times 256$ hypercomplex files with 8 transients for 256 time increments. A mixing time of 600 ms was used and processing was carried out using a sinebell squared function shifted by $\pi / 2$ and a states-TPPI method. High resolution mass spectra were obtained $\mathrm{FAB}^{+}$ionization mode using NBA matrix.

X-ray Diffraction Analysis. The X-ray diffraction data were collected at room temperature on a four circle diffractometer using graphite-monochromated Mo-K $\alpha$ radiation $(\lambda=0.71073 \AA)$. The structure was solved by direct methods using SHELXL 97 and refinement was performed using SHELXL 97³ by the full-matrix least-squares technique with anisotropic thermal factors for heavy atoms. Hydrogen 
atoms were calculated at idealized positions, and during refinement they were allowed to ride on their carrying atom with an isotropic thermal factor fixed to 1.2 times the $U_{\text {eq }}$ value of the carrier atom (1.5 for the methyl protons).

General procedure for the addition of trimethylsilyl cyanide to imines 1a-c. In a typical experiment the appropriate amount of trimethylsilyl cyanide was added to a solution of crude imine 1ac $(1 \mathrm{mmol})$ in the corresponding dry solvent $(10 \mathrm{~mL})$ and the mixture was stirred at the temperature indicated in Table 1 for 3 or $12 \mathrm{~h}$. The reaction mixture was quenched with saturated aqueous $\mathrm{NH}_{4} \mathrm{Cl}$ $(10 \mathrm{~mL})$ and extracted with diethyl ether. The combined organic phases were washed successively with saturated aqueous $\mathrm{NaHCO}_{3}$ and brine and then dried over anhydrous $\mathrm{MgSO}_{4}$. Removal of the solvents in vacuo yielded a crude product containing the corresponding amino nitriles as a mixture of diastereoisomers. This mixture was immediately purified by flash chromatography on a silica gel column using petroleum ether/ethyl acetate (3/1) as eluent.

(R)-2-(Benzylamino)-2-[(S)-2,2-dimethyl-1,3-dioxolan-4-yl]propanenitrile (syn-2a). IR absorption (KBr) 3337, $2221 \mathrm{~cm}^{-1}$; ${ }^{1} \mathrm{H}$ NMR (400 MHz, $\left.\mathrm{CDCl}_{3}\right) \delta$ 7.37-7.24 (m, 5H), 4.20 (dd, $1 \mathrm{H}, J=6.9 \mathrm{~Hz}, J=$ $6.7 \mathrm{~Hz}), 4.11-4.01$ (m, 2H), 3.94-3.86 (m, 2H), 1.78 (bs, 1H), 1.43 (s, 6H), 1.36 (s, 3H); ${ }^{13} \mathrm{C}$ NMR (100 $\left.\mathrm{MHz}, \mathrm{CDCl}_{3}\right) \delta 139.0,128.5,128.0,127.5,120.3,110.4,79.8,64.6,57.3,48.6,26.0,24.9,21.3$. HRMS $\left(\mathrm{FAB}^{+}\right)$calc for $\mathrm{C}_{14} \mathrm{H}_{20} \mathrm{NO}_{2}\left(\mathrm{M}^{+}-\mathrm{CN}\right)$ 234.1494. Found 234.1488.

(S)-2-(Benzylamino)-2-[(S)-2,2-dimethyl-1,3-dioxolan-4-yl]propanenitrile (anti-2a). m.p. = 48-49 ${ }^{\circ} \mathrm{C}$; IR absorption (KBr) 3327, $2219 \mathrm{~cm}^{-1}$; ${ }^{1} \mathrm{H}$ NMR (400 MHz, $\left.\mathrm{CDCl}_{3}\right) \delta$ 7.38-7.25 (m, 5H), 4.12 (dd, $1 \mathrm{H}, J=6.9 \mathrm{~Hz}, J=6.0 \mathrm{~Hz}), 4.06(\mathrm{dd}, 1 \mathrm{H}, J=6.0 \mathrm{~Hz}, J=6.0 \mathrm{~Hz}), 3.99(\mathrm{dd}, 1 \mathrm{H}, J=6.9 \mathrm{~Hz}, J=6.0 \mathrm{~Hz}$ ), 3.94-3.84 (m, 2H), 2.38 (bs, 1H), 1.49 (s, 6H), 1.33 (s, 3H); ${ }^{13} \mathrm{C}$ NMR (100 MHz, $\left.\mathrm{CDCl}_{3}\right) \delta$ 139.0, 128.5, 128.3, 127.4, 119.9, 110.9, 80.2, 65.7, 59.2, 48.7, 26.3, 25.3, 20.5; elemental analysis calcd (\%) for $\mathrm{C}_{15} \mathrm{H}_{20} \mathrm{~N}_{2} \mathrm{O}_{2}$ : C, 69.20; H, 7.74; N, 10.76. Found: C, 69.48; H, 7.65; N, 10.81. 


\section{References}

(1) Leyes, A. E.; Poulter, C. D. Org. Lett. 1999, 1, 1067-1070.

(2) Palomo, C.; Aizpurua, J. M.; García, J. M.; Galarza, R.; Legido, M.; Urchegui, R.; Román, P.;

Luque, A.; Server-Carrió, J.; Linden, A. J. Org. Chem. 1997, 62, 2070-2079.

(3) Sheldrick, G. M.; SHELXL97, Program for the Refinement of Crystal Structures; University of Göttingen: Germany, 1997. 


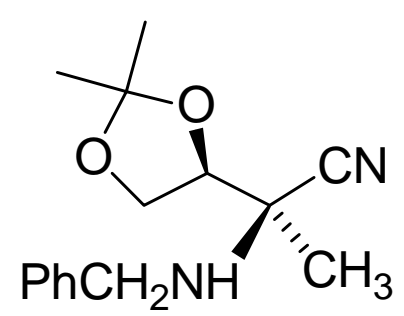

syn $2 a$ 


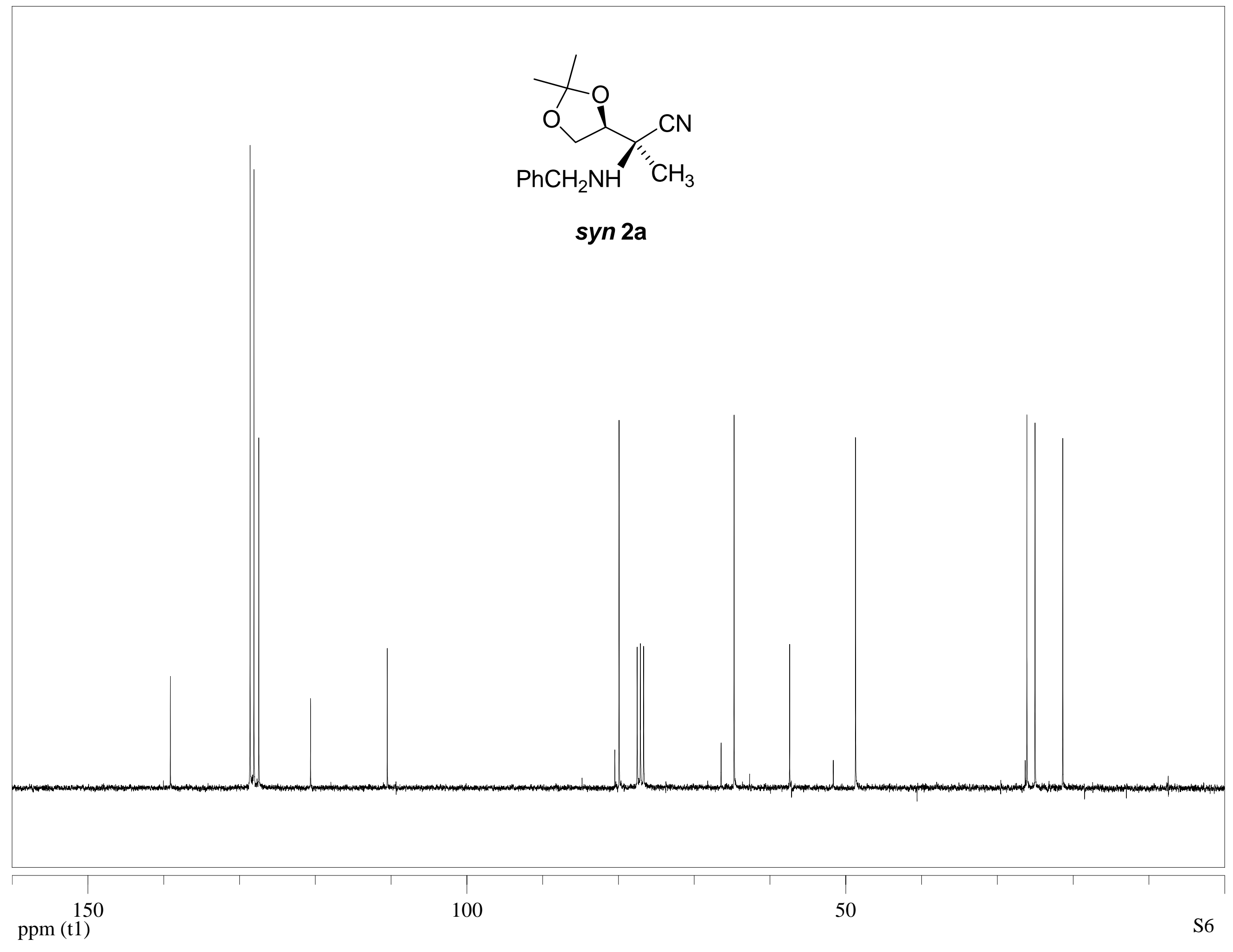




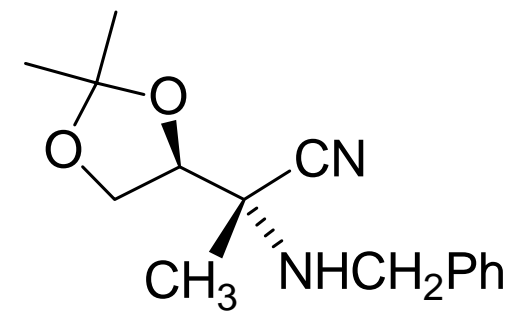

anti 2a 


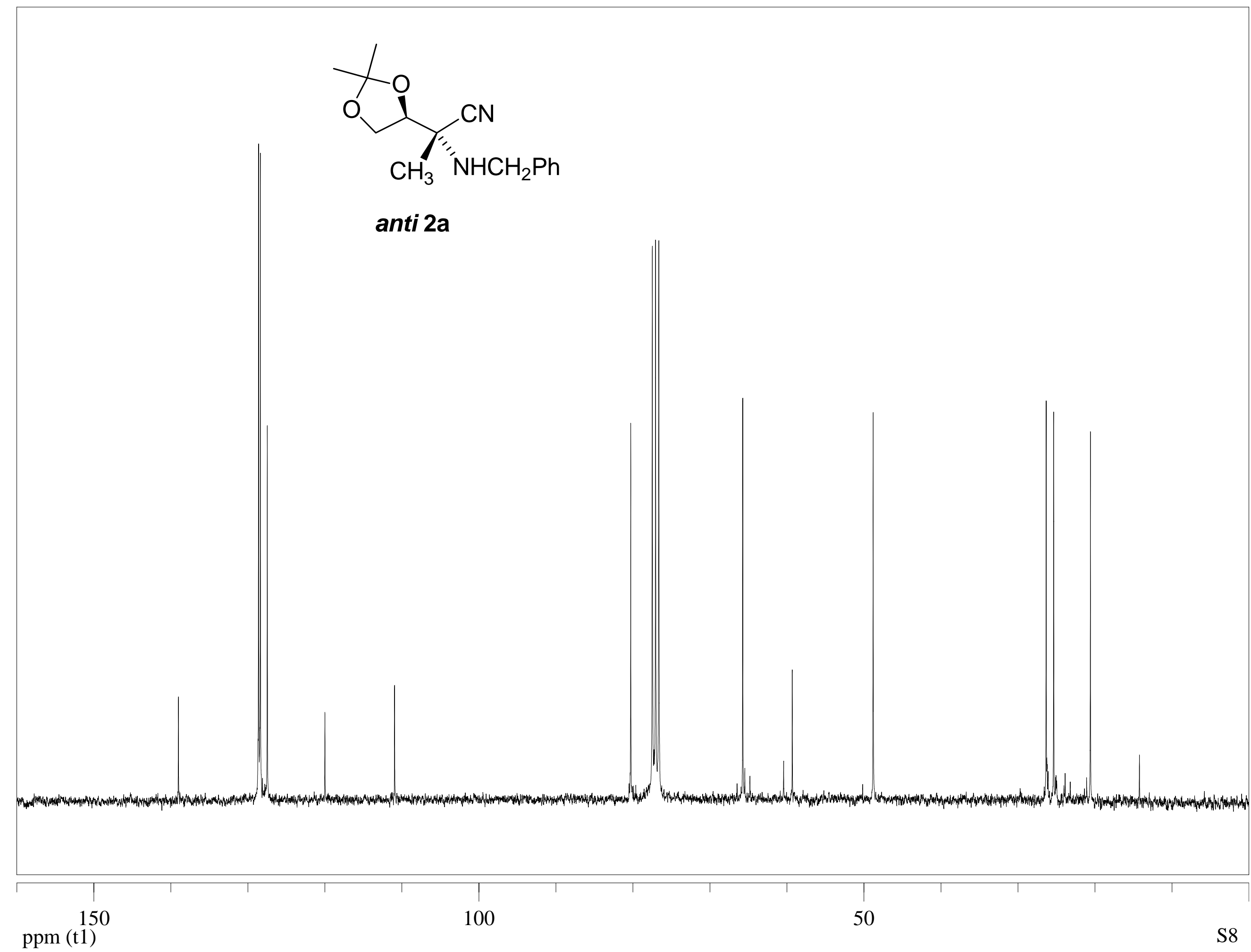




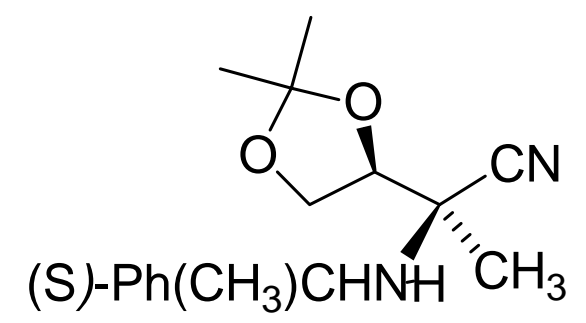

syn 2c
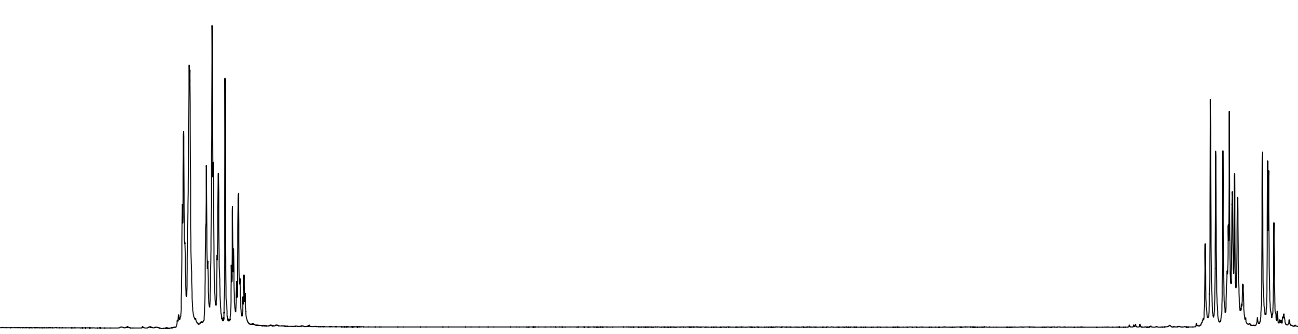

ppm (t1)

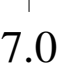

6.0

5.0

4.0

3.0

2.0 


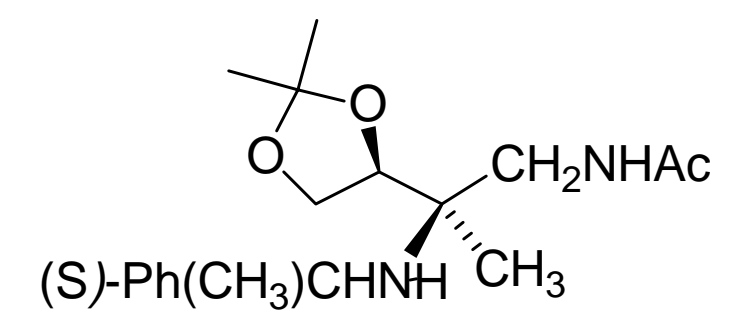

3
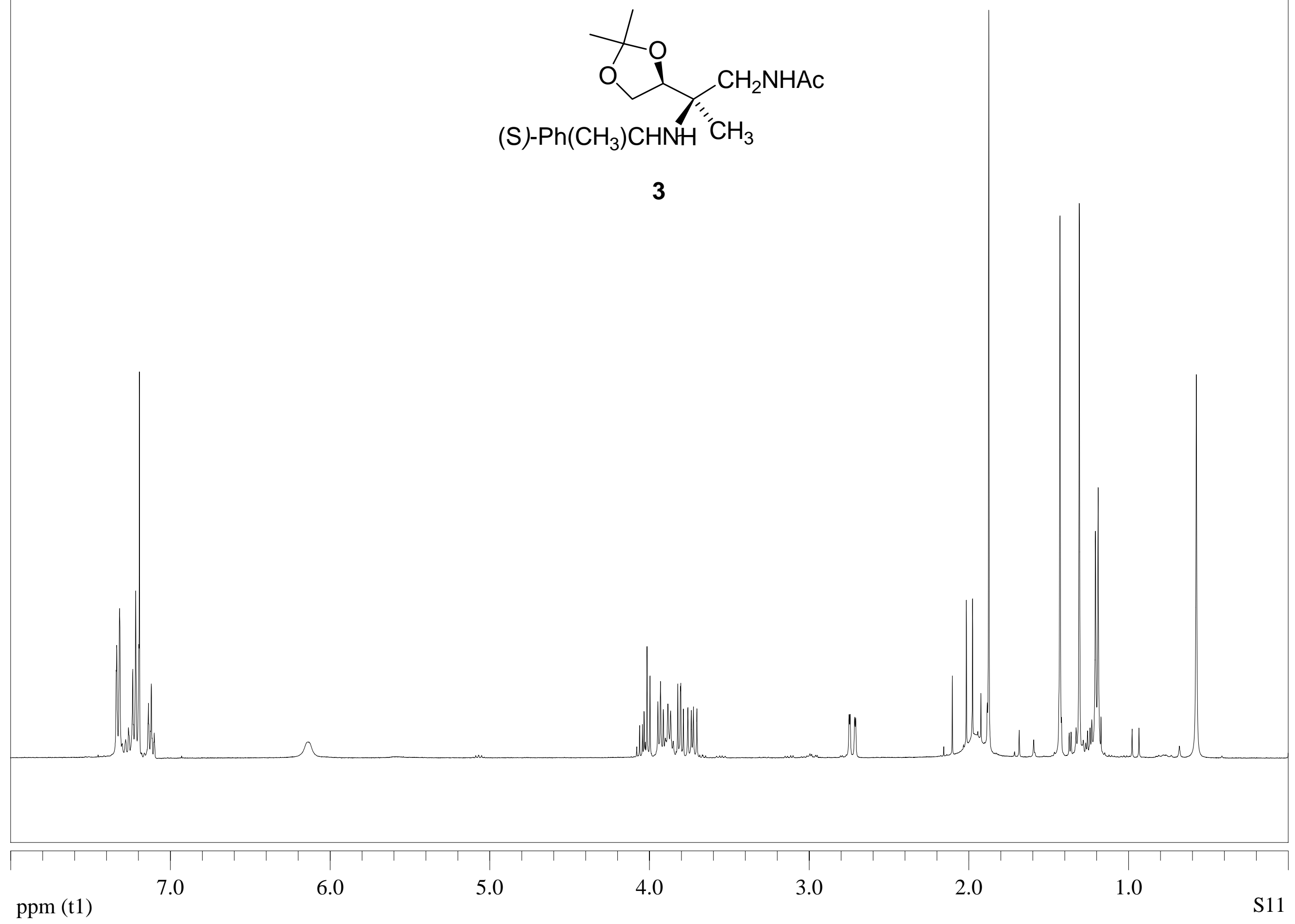


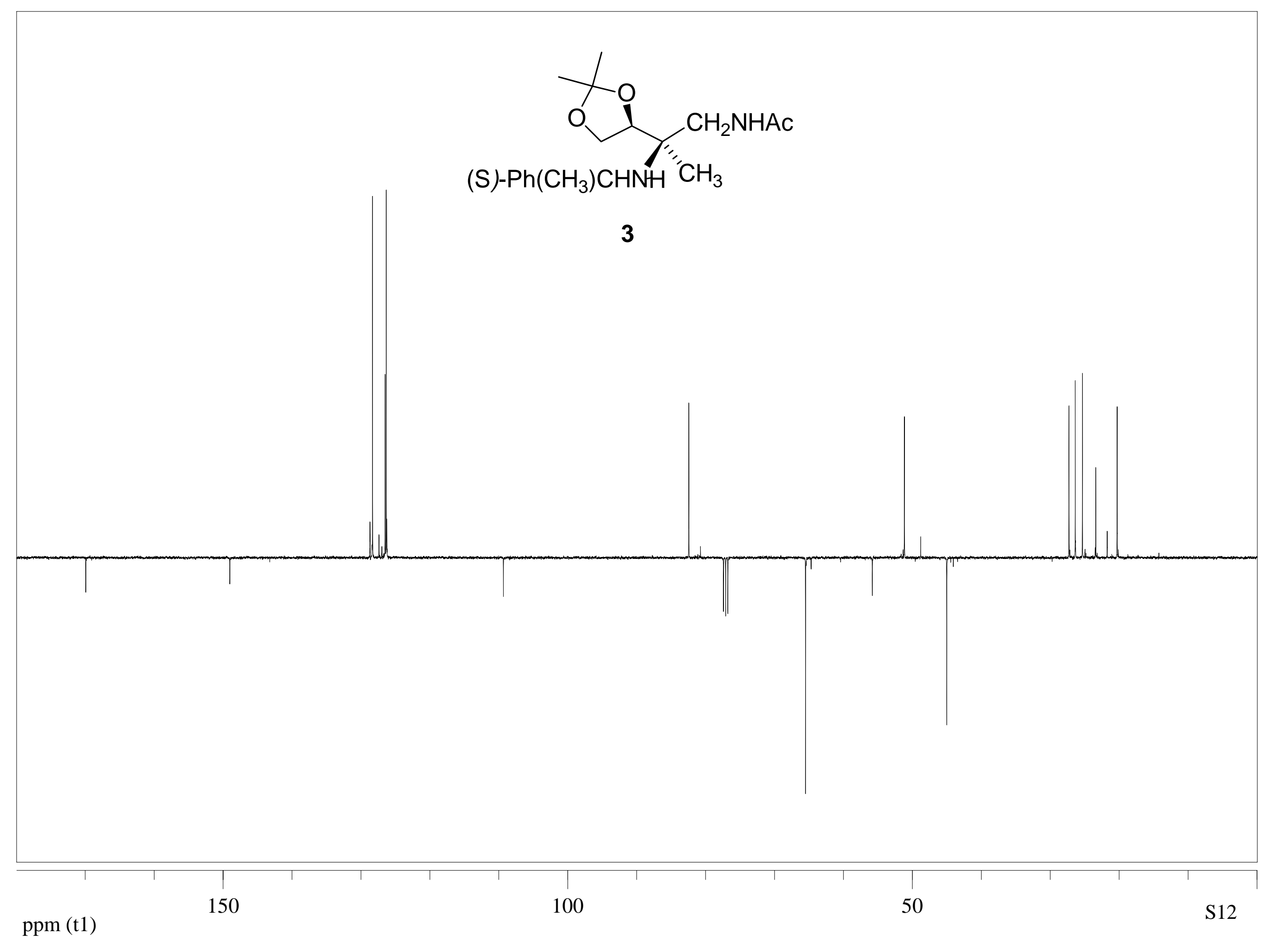




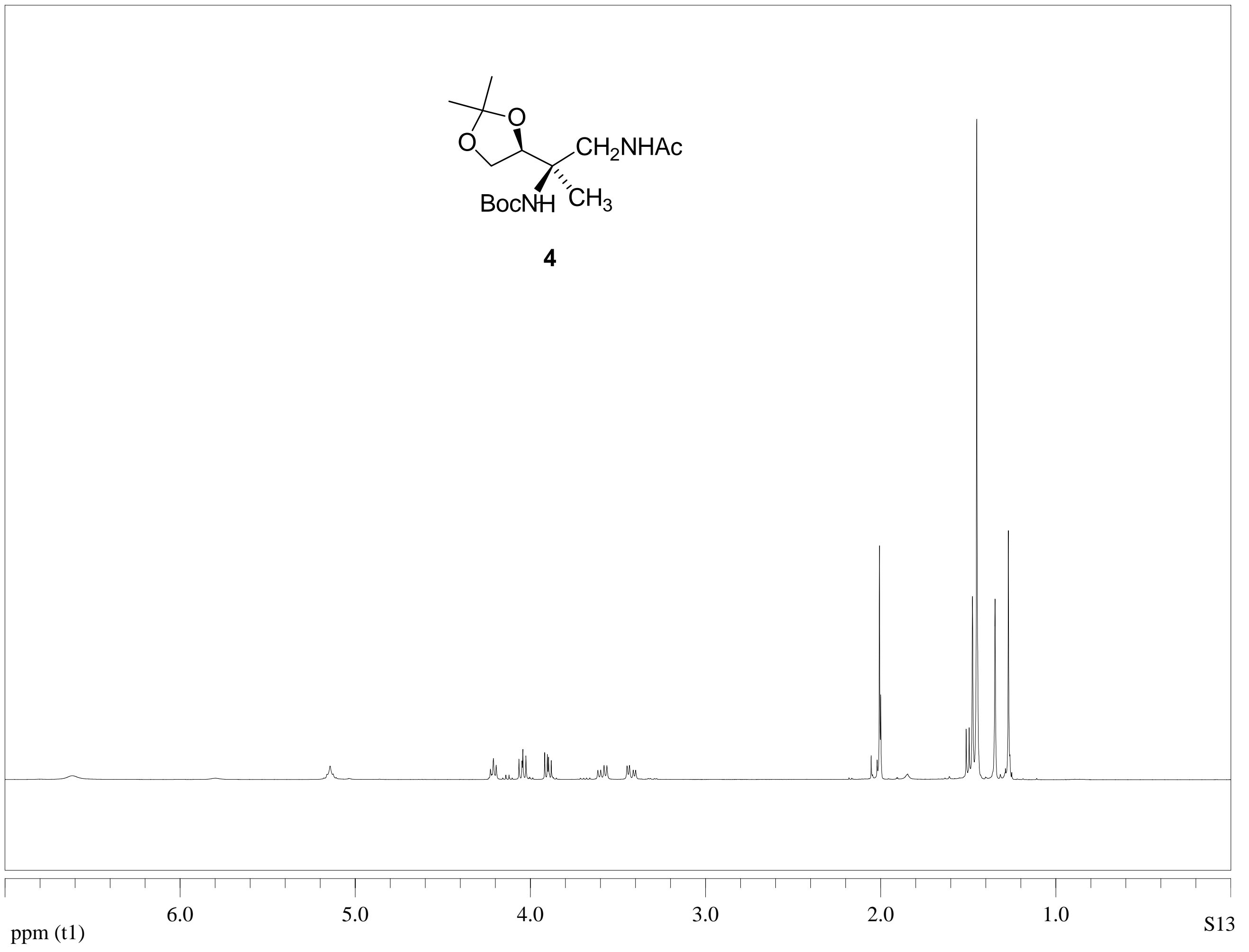




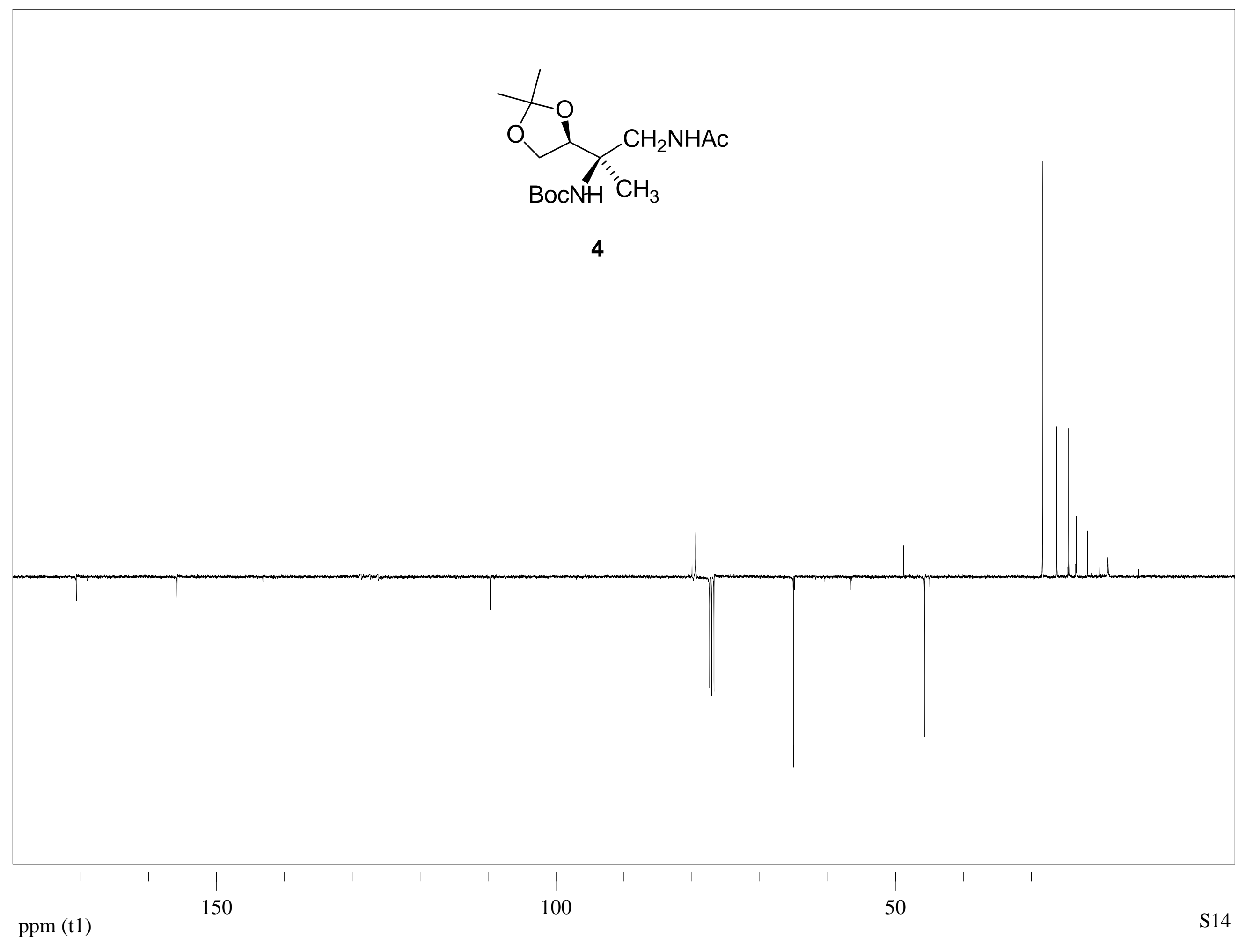




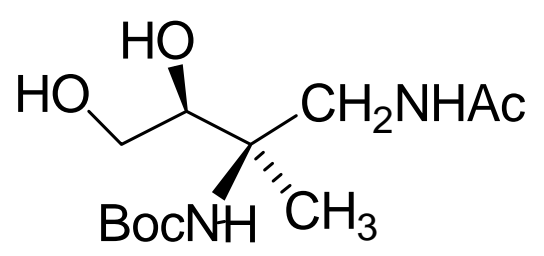

5

ond wh 


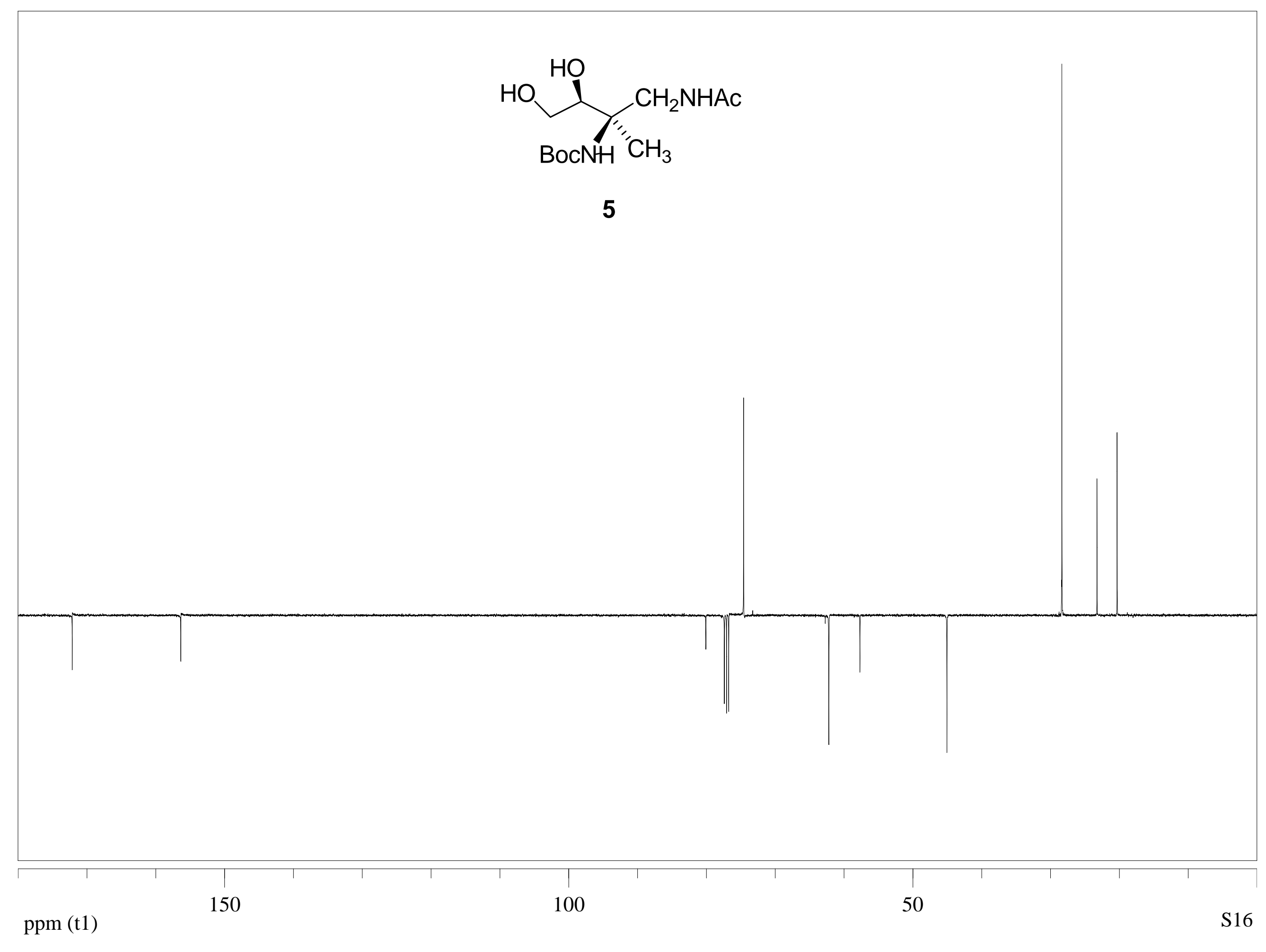




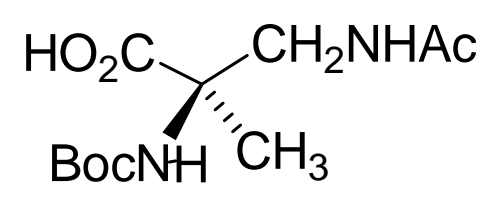

6

Mll Mn 


\section{$\mathrm{HO}_{2} \mathrm{C}-\mathrm{CH}_{2} \mathrm{NHAC}$ \\ $\mathrm{H}=" \mathrm{CH}_{3}$}

6

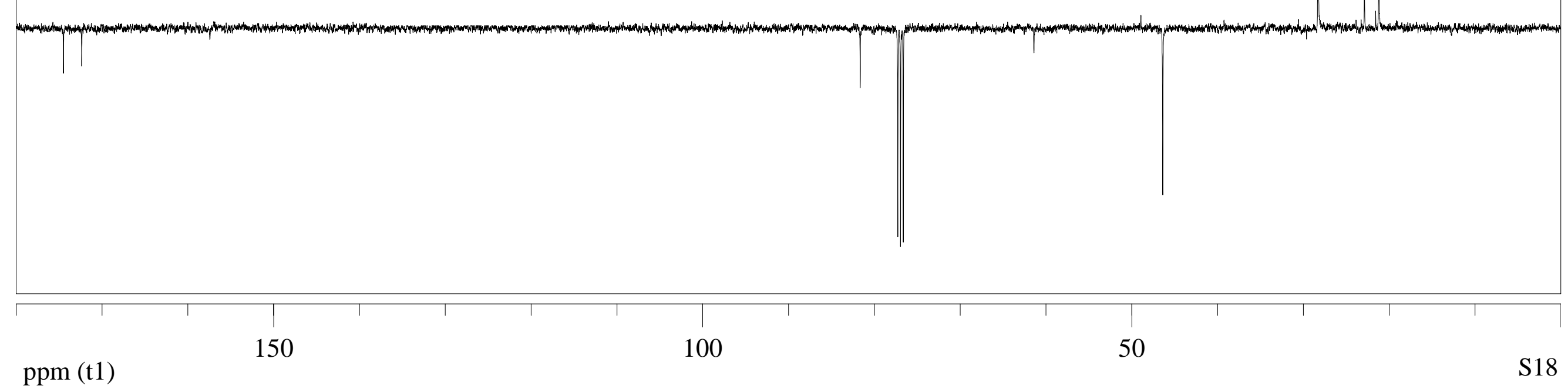


Figure 1

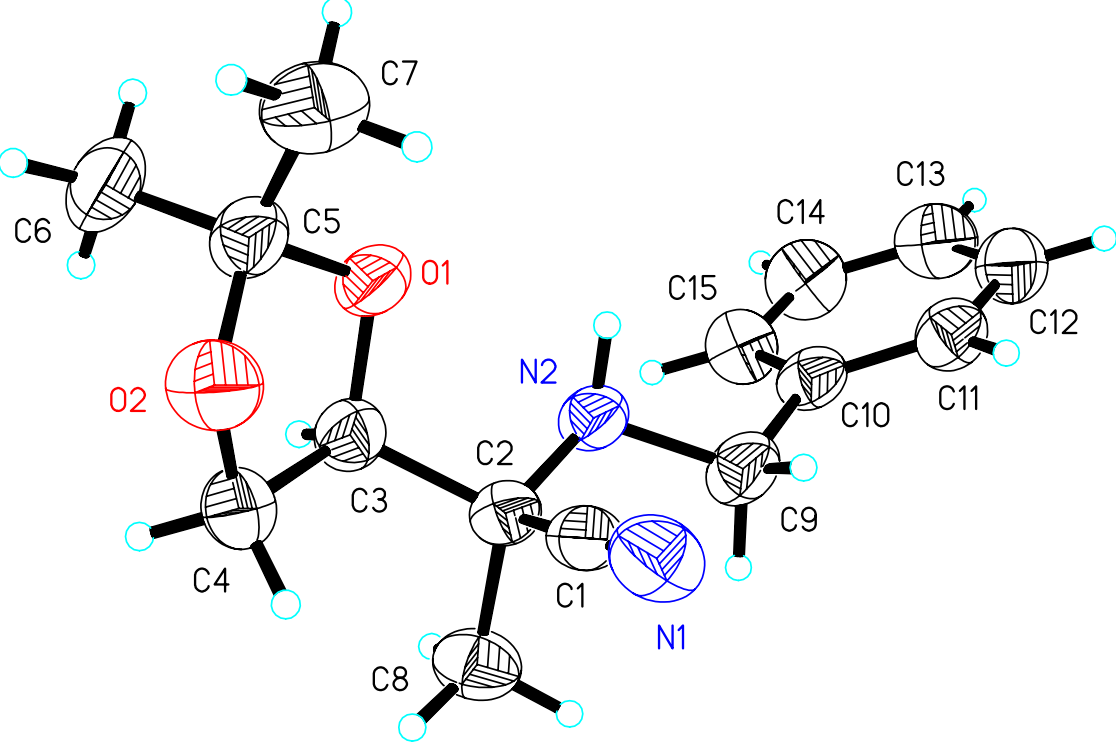

